\title{
Uma Experiência de uso da Gamificação em Plataformas de Participação Social
}

\author{
Tadeu Classe ${ }^{1,2}$, Jonas Silva ${ }^{1,2}$, Mariano Pimentel ${ }^{2}$, Renata Araujo ${ }^{1,2}$ \\ ${ }^{1}$ Sistemas de Informação de Governo Abertos e Participativos (SIGAC) \\ Núcleo de Pesquisa e Inovação em Ciberdemocracia (CIBERDEM) \\ ${ }^{2}$ Programa de Pós-Graduação em Informática \\ Universidade Federal do Estado do Rio de Janeiro (UNIRIO) \\ Rio de Janeiro - RJ - Brasil \\ \{tadeu.classe, jonas.silva, pimentel, renata.araujo\}@uniriotec.br
}

\begin{abstract}
The research areas in e-Democracy and e-Participation have explored solutions to decrease the gap between government and citizens with the use of ICTs. Although we can find proposals of technological solutions for citizen participation in public issues, this collaboration does not seem to happen easily. Platforms created frequently shows low participation levels. In the aim to promote participation, this work discusses preliminary studies on the use of gamification as a trigger to citizen engagement in e-participation. The paper was based on Design Science Research methodology presenting the building of an e-participation platform with gamification elements as research artifact. The platform was evaluates in a real public context (experimental study) in order to investigate if the gamification mechanics promotes a larger participation, and a questionnaire (quantitative study) in order to evaluate the proposal. Particularly, the results of the evaluation indicates a greater participation in the use of the gamified platform, mostly when extrinsic motivation resources are applied.
\end{abstract}

Resumo. As áreas de pesquisa em Democracia e Participação Eletrônica têm explorado soluções para diminuir o distanciamento habitual na relação entre governo e cidadãos com o uso de TICs. Apesar de terem sido propostas alternativas tecnológicas para a participação cidadã em assuntos de governo, esta colaboração não tem ocorrido facilmente. As plataformas criadas apresentam, na maioria dos casos, baixa audiência. Na tentativa de promover a participação, este trabalho explora o uso de mecanismos de gamificação como gatilho motivador ao engajamento de cidadãos em plataformas de participação social. Este artigo se baseou na metodologia Design Science Reaseach, apresentando a criação de uma plataforma de participação social com elementos de gamificação como artefato de pesquisa. A plataforma foi submetida a uma avaliação em um contexto real (estudo experimental) no intuito de averiguar se os mecanismos de gamificação promovem uma maior participação dos envolvidos. Além de um questionário (estudo qualitativo) a fim de avaliar a proposta. Os resultados da avaliação demonstram em particular, uma maior participação com o uso da plataforma gamificada, sobretudo quando recursos de motivação extrínseca são aplicados.

ClASSE, T.; SILVA, J.; PIMENTEL, M.; ARAUJO, R.

Uma Experiência de uso da Gamificação em Plataformas de Participação Social

isys - Revista Brasileira de Sistemas de Informação, Rio de Janeiro, vol. 9, No. 1, pp. 58-80, 2016 


\section{Introdução}

A evolução da forma de criar e disseminar informação através dos recursos existentes na Web promovem mudanças significativas na sociedade. Como exemplo disso, pode se observar a maneira com que as mídias sociais influenciam a forma com que as pessoas se comunicam, colaboram, trabalham e aprendem [Effing et al., 2011]. Um mundo cada vez mais conectado abre novas oportunidades tanto para organizações inovarem em seus negócios, quanto para clientes adquirirem mais autonomia e satisfação no uso dos serviços [Magdaleno e Araujo, 2015].

Esta oportunidade também surge para as instituições públicas e governamentais, onde a interação com seus clientes principais - os cidadãos - é cada vez mais almejada [Araujo et al. 2011]. Contudo, em relação a organizações públicas e cidadãos, historicamente e culturalmente, existe um distanciamento entre estes, os governos julgam que o cidadão não está apto para discutir, entender e contribuir com as instituições públicas, e os cidadãos pensam que os processos governamentais são muito complexos e burocráticos [Magdaleno e Araujo, 2015][Santos et al., 2015b].

A participação cidadã por meio do uso de tecnologias da informação e comunicação (TICs) pode contribuir para a melhoria dos serviços públicos, pois estas possibilitam aos cidadãos debaterem sobre estes serviços, propor melhorias, acompanhar e fiscalizar a aplicação de recursos, e, no limite, participar do ciclo de políticas públicas, desde a elaboração até a execução e monitoramento [Santos et al., 2015a]. O engajamento nas plataformas de participação social é sempre desejado, visto que a contribuição contínua dos membros é fundamental para a vida e sustentabilidade dessas comunidades, de modo que com contribuições contínuas e voluntárias, os membros podem interagir e colaborarem entre si, e, em muitos casos, gerarem ideias e soluções para problemas muitas vezes complexos [Kleinman et al., 2009].

No entanto, a participação e a colaboração dos indivíduos em plataformas colaborativas não acontecem de maneira uniforme. Segundo Nielsen (2006) existe a "regra da participação desigual", que consiste em dizer que em comunidades virtuais, $90 \%$ dos seus usuários nunca contribuíram, 9\% contribuem pouco e apenas $1 \%$ dos envolvidos participam ativamente.

Apesar das iniciativas voltadas à participação, o engajamento das pessoas não acontece como desejado [Effing et al., 2011]. Em uma pesquisa realizada sobre o uso da plataforma de participação social Portal e-Democracia da Câmara dos Deputados do Brasil com 200 cidadãos, mostrou que 37,1\% dos usuários que participam da pesquisa não acompanharam alguma discussão no Portal [Freire e Stabile 2013]. As plataformas de participação social Participa.br ${ }^{1}$ e Dialoga Brasil ${ }^{2}$, iniciativas do Governo Federal, possuem, respectivamente, 15.387 e 11.077 usuários [Participa.br, 2015] [Dialoga, 2015], quantitativo de usuários bem aquém do número de cidadãos brasileiros, públicoalvo destas plataformas.

$\mathrm{Na}$ tentativa de fazer com que os cidadãos dialoguem com as instituições públicas sobre problemas e proponham possíveis soluções por meio de plataformas de participação social, é necessário pensar em formas de os atrair (motivar) e fazer com que contribuam. Para tal fim, a gamificação é apontada como uma possível ferramenta a

\footnotetext{
${ }^{1}$ Participa.br: http://www.participa.br/

${ }^{2}$ Dialoga Brasil: http://dialoga.gov.br/
} 
ser utilizada, pois fornece meios de tornar as tarefas mais desafiadoras, atrativas e prazerosas [Hamari et al., 2014].

No intuito de promover o aumento da participação dos cidadãos em plataformas de participação social, neste trabalho foi realizado um estudo sobre o uso de elementos de gamificação neste contexto. A abordagem da Design Science Research (DSR) foi utilizada para conduzir essa investigação científica, sendo desenvolvido um artefato - a Plataforma de Participação Social Ouvidoria Social. A gamificação do artefato seguiu alguns dos mecanismos mais comuns destacados por Bista e colaboradores $(2012,2014)$ como: desafios, badges, ranking, pontuação, níveis e barras de progresso. A avaliação da influência da gamificação no uso da plataforma Ouvidoria Social foi realizada através de estudo experimental e análise qualitativa com alunos da Universidade Federal do Estado do Rio de Janeiro (UNIRIO).

Este trabalho está organizado da seguinte maneira: na Seção 2 é apresentado o referencial teórico; na Seção 3, estão presentes alguns trabalhos relacionados à esta pesquisa; a Seção 4 aborda o método de pesquisa utilizado neste trabalho; na Seção 5, é apresentada a proposta de solução através do protótipo da plataforma de participação social gamificada (Ouvidoria Social); a Seção 6 possui a avaliação da proposta de solução, no qual é apresentado o planejamento e execução dos estudos quantitativos e qualitativos, discutido e analisado os resultados encontrados; e a Seção 7 expõe a conclusão do artigo.

\section{Referencial Teórico}

\subsection{Participação Eletrônica}

A participação eletrônica (e-participação) tem o objetivo de promover o diálogo entre a sociedade civil e as instâncias governamentais por meio do uso de tecnologias da informação e comunicação (TICs). $\mathrm{O}$ aumento da capacidade de participação (empoderamento) do cidadão nas decisões do governo é, também, um dos objetivos da e-participação, através destas iniciativas os cidadãos e outros atores da sociedade civil podem influenciar no ciclo de políticas públicas, na execução de serviços públicos, no processo legislativo, entre outras ações do governo [Sæbø et al., 2008].

A pesquisa em participação eletrônica entende que a participação por meio de TICs se dá em níveis e diversas classificações foram propostas, a observação destes é importante para o planejamento das iniciativas de participação social e construção das plataformas de participação social, contribuindo para a identificação dos requisitos dos sistemas [Araujo et al., 2011].

Nos níveis iniciais de participação social ou cidadã a comunicação é predominantemente unidirecional, a administração pública se concentra na prestação de serviços públicos e no fornecimento de informações sobre estes para o cidadão com $o$ objetivo de tornar a prestação de serviços mais eficiente, são realizadas consultas públicas para tomar decisões políticas a partir da opinião da sociedade civil [Gomes 2004 apud Araujo et al., 2011], o cidadão deve receber informações sobre política e cidadania [Tambouris et al., 2007], desta forma a esfera civil estará apta a exercer uma participação mais ativa.

Já nos níveis mais avançados de participação cidadã, conforme diversas classificações [Macintosh 2004][Gomes 2004 apud Araujo et al., 2011][Tambouris et

CLASSE, T.; SILVA, J.; PIMENTEL, M.; ARAUJO, R.

Uma Experiência de uso da Gamificação em Plataformas de Participação Social

iSys - Revista Brasileira de Sistemas de Informação, Rio de Janeiro, vol. 9, No. 1, pp. 58-80, 2016 
al., 2007], ocorre maior engajamento da sociedade civil. Nestes níveis a comunicação cidadão-governo é bidirecional, é praticado o maior controle social sobre as ações governamentais a partir da prestação de contas e maior transparência do governo. $\mathrm{O}$ cidadão participa das decisões políticas juntamente com as instâncias governamentais e os representantes políticos, a esfera civil passa a colaborar no ciclo de políticas públicas, a parceria entre a esfera civil e o governo é estabelecida. No último nível de participação, a tomada de decisão é delegada a sociedade civil.

A participação eletrônica é praticada através de plataformas de participação social, também chamadas de ambientes virtuais de participação social, que são sistemas disponibilizados na Web e/ou para dispositivos móveis, que possibilitam o exercício da participação eletrônica, permitindo que os interessados dialoguem sobre serviços públicos, políticas públicas, e outros temas de interesse da sociedade civil, nos diversos níveis de participação [Silva e Araujo, 2015].

Por meio destas plataformas podem ser discutidos temas de interesse público e a partir destas formular propostas sobre estes; realizar a fiscalização, propor melhorias ou avaliar serviços disponibilizados pela administração pública; analisar e criticar projetos de lei em tramitação; entre outras possibilidades. São alguns exemplos de plataformas de participação social: Participa.br, Dialoga Brasil, Plataforma Brasil ${ }^{3}$, Visão Rio $500^{4}$ e Desafio Ágora Rio5.

\subsection{Gamificação}

O termo gamificação teve sua origem na indústria da mídia digital e foi utilizado pela primeira vez em meados de 2008. Uma aceitação generalizada sobre o termo ocorreu a partir da segunda metade de 2010 com o trabalho Deterding e colaboradores (2011), o qual definiu gamificação como "o uso de elementos de design de jogos em contextos não jogáveis”. Blohm e Leimeister (2013) assumem que gamificação é uma tecnologia persuasiva capaz de influenciar o comportamento dos usuários.

Em síntese, pode-se dizer que gamificação são abordagens que usam conceitos e mecanismos existentes nos jogos para ajudar os usuários a interagirem e se engajarem com ferramentas ou entre si, em diferentes tipos de domínios [Simões et al., 2013]. Em outras palavras, gamificação consiste na criação e utilização de técnicas e ferramentas capazes de engajar, fidelizar e promover mudanças no comportamento das pessoas através de mecanismos existentes em jogos [Simões et al., 2013] [Blohm e Leimeister, 2013].

Nos últimos anos, gamificação vem sendo estudada como uma maneira de prestar suporte ao engajamento de usuários e reforçar os padrões positivos no uso de recursos e serviços como: aumento das atividades dos envolvidos, interação social ou qualidade e produtividade de tarefas em diferentes tipos de abordagens e ferramentas sociais [Silva e Prado, 2015]. O contexto de gamificação está sendo explorado principalmente na área de marketing, porém suas aplicações se estendem a outras áreas como: saúde, governo e educação [Simões et al., 2013][Silva e Prado, 2015].

\footnotetext{
${ }^{3}$ Plataforma Brasil: https://plataformabrasil.org.br/

${ }^{4}$ Visão Rio 500: http://www.visaorio500.rio/

5 Desafio Ágora Rio: https://desafioagorario.crowdicity.com/

CLASSE, T.; SILVA, J.; PIMENTEL, M.; ARAUJO, R.

Uma Experiência de uso da Gamificação em Plataformas de Participação Social

iSys - Revista Brasileira de Sistemas de Informação, Rio de Janeiro, vol. 9, No. 1, pp. 58-80, 2016
} 
O uso de elementos de jogos em um processo ou atividade consiste na reestruturação e transformação destes em uma experiência parecida com um jogo para o participante. Este é um processo que precisa da decomposição dos jogos atuais em pequenas partes que possam ser utilizadas, e após isso, selecionar aquelas aplicáveis à motivação e ao engajamento [Lounis et al., 2014]. O objetivo, então, é inserir a dinâmica de jogos dentro de tarefas que se apresentem como desinteressantes ou monótonas, para torná-las mais divertidas e assim fazer com que as pessoas participem e colaborem frequentemente [Bista et al., 2014].

A implantação de mecanismos de gamificação requer a análise do contexto e quais são as estratégias que poderão ser empregadas para prover a experiência aos usuários [Silva e Prado, 2015]. Gartner (2015) elenca quatro princípios que gamificação fornece para guiar o comprometimento do usuário: i) feedbacks acelerados; ii) objetivos e regras claras; iii) narrativas envolventes; e iv) tarefas desafiadoras, mas que possam ser atingidas. O design de qualquer processo gamificado deve tentar incorporar um ou todos estes princípios [Bista et al., 2012].

Tratando-se de mecanismos de gamificação para engajamento e participação, dentre as técnicas mais utilizadas se destacam: i) Pontuação, utilizada para trilhar e intensificar a participação; ii) Insígnias, representação visual das conquistas e objetivos alcançados; iii) Habilidades ou Reputação, mostra as preferências e características para possíveis alianças; iv) Placares, usados para fazer comparação entre os envolvidos; v) Níveis de Progresso, níveis que incentivam a participação e a conclusão de tarefas; vi) Desafios, incentiva à resolução de tarefas; e vii) Recompensas, motiva o usuário [Bista et al., 2014][Bista et al., 2012].

Em relação a recompensa, dois tipos se destacam: a intrínseca que consiste na recompensa psicológica, no sentimento de tarefa cumprida e no reconhecimento; e a extrínseca, que se baseia no ganho real, onde existem recompensas lucrativas para os participantes [Bista et al., 2012][Richard e Edward, 2000]. Estes mecanismos influenciam diretamente nas questões relacionadas à colaboração e resultados. Avaliando o impacto de tais técnicas e recompensas é possível concluir como a gamificação promove o comprometimento dos membros de uma comunidade [Bista et al., 2014].

Bista e colaboradores (2012) argumentam que uma técnica de gamificação não deve ser utilizada sozinha, a escolha destas dependerá do contexto da aplicação, do objetivo e dos níveis de gamificação a que este contexto se refere, caso tais técnicas não serem bem aplicadas, existe um grande risco de que todo o processo falhe [Silva e Prado, 2015].

Os cenários mais comuns onde jogos ou elementos de jogos são aplicados e facilmente encontrados são em educação e aprendizagem [Connolly et al., 2012] [Hamari et al., 2014]. Neste contexto jogos podem fornecer suporte a aquisição de conhecimento, estimular e motivar a participação dos usuários [Connolly et al., 2012]. Jogos quando aplicados de modo a estimular o pensamento crítico e aprendizagem, tem o potencial de introduzir indivíduos em novos domínios, gerando grupos sociais capazes de aprender, sugerir e resolver questões sobre estes domínios [Gee, 2007].

A objetivo do uso da gamificação em contextos públicos é tentar engajar cidadãos, servidores, gestores, dentre outros envolvidos com atividades públicas, em processos de participação eletrônica e fazer com que eles contribuam com os temas de

ClASSE, T.; SILVA, J.; PIMENTEL, M.; ARAUJO, R.

Uma Experiência de uso da Gamificação em Plataformas de Participação Social

iSys - Revista Brasileira de Sistemas de Informação, Rio de Janeiro, vol. 9, No. 1, pp. 58-80, 2016 
interesse da sociedade, através de ideias, sugestões e propostas que possam ser apresentadas para organizações públicas.

Em ambientes de participação eletrônica, o uso da gamificação pode fazer com que o os cidadãos sejam mais participativos [Thiel, 2015] e que seu interesse por assuntos democráticos aumente, pois por natureza as pessoas são motivadas por jogos, pois estes podem gerar sentimento de reconhecimento e satisfação, permitindo que aquelas pessoas que estão envolvidas possam se sentir úteis, possibilitando contribuições voluntárias [Classe e Araujo, 2015].

\section{Trabalhos Relacionados}

A gamificação como uma abordagem que pode promover a participação social em processos públicos através da participação eletrônica foi suscitada por Classe e Araujo (2015). Neste trabalho foi feito um mapeamento sistemático com o objetivo de identificar quais pesquisas científicas estão sendo conduzidos sobre o uso de gamificação em processos públicos. Concluiu-se que não foram encontrados trabalhos científicos relevantes associando os temas gamificação, serviços públicos e Business Process Management (BPM), entretanto, existem trabalhos que abordem gamificação de processos sem que haja relação com organizações públicas.

Em seu trabalho, Baykurt (2012) desenvolveu um sistema Web baseada em elementos de jogos que permite aos cidadãos de uma vizinhança relatarem problemas. Os cidadãos envolvidos afirmaram que tais mecanismos empregados no sistema permitiram um melhor relacionamento entre eles, onde podiam acompanhar resoluções de problemas e colaborarem com conciliações.

Moradian e colaboradores (2014) apresentaram o design de um sistema com elementos de gamificação (objetivo, progresso, pontos e placares) para incentivar a participação na geração de ideias em brainstorms colaborativos. Foi realizado um estudo envolvendo estudantes de graduação na criação de ideias para atingir objetivos em comum. Nos resultados preliminares, houve a indicação de que os mecanismos de gamificação ajudaram os estudantes a produzir mais ideias e se engajarem em mais discussões.

Horita e colaboradores (2014) apresentaram o desenvolvimento e implantação de uma arquitetura social com gamificação para conseguir atrair e engajar jovens voluntários em desastres naturais, com o objetivo de melhorar o gerenciamento de atividades e disseminação de informações entre eles. Aplicados em um cenário teste, constataram a maior atenção dos jovens nos processos além da melhoria de comunicação e atendimento de tarefas.

Lounis e colaboradores (2014) verificaram o impacto de dois elementos de jogos (incentivo e colaboração comunitária) na participação dos usuários durante o uso e execução de um serviço com gamificação, tal princípio se deu a partir da percepção de que em alguns jogos, existem objetivos que necessitam de colaboração dos jogadores para que a tarefa possa ser realizada. Os autores propuseram o serviço de compras online com consciência ecológica, onde seus usuários são motivados a fazer compras que gerem menores impactos ambientais. Como resultados, foi constatado que com os elementos de gamificação os participantes colaboraram mais entre si na obtenção dos objetivos em comum, gerando o sentimento de dever cumprido entre eles e por consequência, a vontade de continuar participando.

CLASSE, T.; SILVA, J.; PIMENTEL, M.; ARAUJO, R.

Uma Experiência de uso da Gamificação em Plataformas de Participação Social

isys - Revista Brasileira de Sistemas de Informação, Rio de Janeiro, vol. 9, No. 1, pp. 58-80, 2016 
Bista e colaboradores $(2014,2012)$ propõem uma abordagem com gamificação para os funcionários do departamento de serviços humanos do governo australiano, a fim de que os processos departamentais fossem discutidos e melhorados pelos próprios colaboradores. No trabalho são utilizadas técnicas como pontuação, insígnias e placares na tentativa de fazer com que os funcionários se sintam motivados a participar. Em uma análise preliminar, os autores indicaram que foi constatado que os mecanismos empregados aceleraram o feedback entre os participantes e que o engajamento entre os funcionários para a resolução de tarefas comuns aumentou. Além disso, os mecanismos de gamificação utilizados seriam utilizados como métricas para monitorar $o$ comportamento da comunidade.

\section{Metodologia de Pesquisa}

Os paradigmas tradicionais de pesquisa, qualitativos e quantitativos, resultam em estudos que se concentram em explicar, descrever, explorar ou predizer fenômenos e suas relações, mas quando a investigação científica está relacionada ao estudo de projetos, construção e criação de novos artefatos, ou pesquisas orientadas a resolução de problemas, a design science (ciência do projeto ou ciência do artificial) se revela mais adequada. A design science research (DSR) é o método de pesquisa que operacionaliza a investigação fundamentada no paradigma da design science [Dresch et al., 2015].

Na DSR, o projeto responde a perguntas relevantes para os problemas humanos através da criação de artefatos inovadores, que podem ser modelos, métodos, instanciações (protótipos de sistemas), constructos, entre outras produtos, contribuindo para o corpo do conhecimento científico [Recker, 2012]. Os artefatos são projetados com base em conjecturas teóricas fundamentadas na Ciência do Comportamento, e a avaliação destes fornece novos dados sobre as conjecturas que foram formuladas com o objetivo de aumentar o conhecimento teórico [Rocha et al., 2015].

As diretrizes para o método DSR, propostas por Hevner e colaboradores (2004), foram utilizadas para guiar esta pesquisa. Conforme estas, os conhecimentos necessários para sua condução devem estar associados aos paradigmas da Ciência do Comportamento e Ciência do Design. A Ciência do Comportamento está relacionada ao desenvolvimento de teorias que explicam ou predizem fenômenos relacionados às necessidades identificadas para o negócio. No paradigma da Ciência do Design, a investigação da pesquisa está relacionada ao desenvolvimento e avaliação dos artefatos projetados para atender as necessidades identificadas para o negócio.

A presente pesquisa utilizou a design science research para investigar se o uso de mecanismos de gamificação em plataformas de participação social promove o aumento de participação dos cidadãos nestes ambientes. Esta conjectura é fundamentada na ciência do comportamento expressa no behaviorismo radical, conforme este, a natureza dota o indivíduo de certas motivações, mas ao longo do seu desenvolvimento a interação com o ambiente lhe atribui outras. $\mathrm{O}$ reforço positivo, que ocorre quando $\mathrm{o}$ comportamento é seguido de um estímulo recompensador, pode aumentar a probabilidade de um comportamento se repetir quando há uma recompensa [Menezes et al., 2014].

Com base em requisitos comportamentais, fundamentados na conjectura supracitada e requisitos de design inerentes a ambientes virtuais onde a participação social pode ser exercitada, foi desenvolvida a Plataforma de Participação Social Ouvidoria Social. Esta foi apresentada em um contexto real de participação eletrônica e

CLASSE, T.; SILVA, J.; PIMENTEL, M.; ARAUJO, R.

Uma Experiência de uso da Gamificação em Plataformas de Participação Social

iSys - Revista Brasileira de Sistemas de Informação, Rio de Janeiro, vol. 9, No. 1, pp. 58-80, 2016 
disponibilizada para os alunos (cidadãos) de uma disciplina do curso de graduação em Sistemas de Informação da UNIRIO (instituição pública prestadora de serviços), sendo este o cenário onde foi realizado o estudo experimental para avaliar se a conjectura que foi proposta é válida. Os elementos desta pesquisa, conforme as características e fundamentos referentes a Design Science Research, são apresentados na Figura 1.

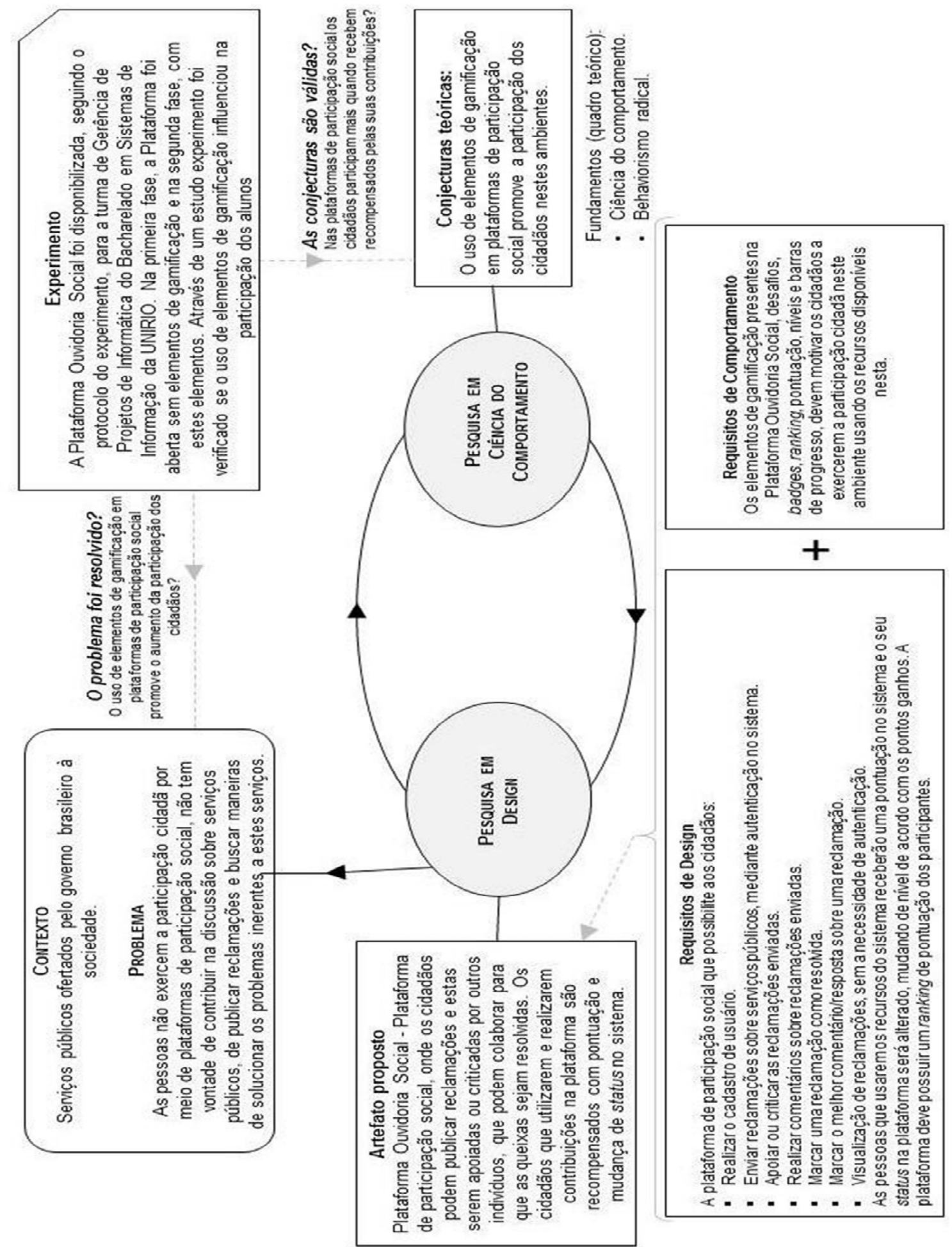

Figura 1. Mapa da Pesquisa conforme a Design Science Research.

CLASSE, T.; SILVA, J.; PIMENTEL, M.; ARAUJO, R.

Uma Experiência de uso da Gamificação em Plataformas de Participação Social

iSys - Revista Brasileira de Sistemas de Informação, Rio de Janeiro, vol. 9, No. 1, pp. 58-80, 2016 


\section{Proposta de Solução}

A Plataforma de Participação Social Ouvidoria Social ${ }^{6,7}$ é um protótipo de um ambiente virtual de participação social que possui elementos de gamificação, onde os usuários podem relatar problemas (reclamações), compartilhar visões, sugerir soluções sobre assuntos relacionados a uma instituição e apoiar ou criticar estas reclamações.

Por exemplo: um aluno pode se sentir incomodado com a limpeza dos corredores da UNIRIO, mas não sabe a quem relatar tal situação, colocando o problema na Plataforma é possível que outros usuários possam sugerir maneiras de solucionar o problema. Este é um cenário simples, porem, pensando em instituições maiores, como prefeitura, bancos, entre outros, é possível que esta plataforma seja útil para os cidadãos, onde estes podem construir soluções de forma colaborativa para os problemas que vivenciam.

A Plataforma foi desenvolvida com o objetivo de fornecer uma interface baseada em mídias sociais, ou seja, que permita a interação dos seus usuários através de perfis personalizáveis, possibilidade de comentários, curtidas, descurtidas, visualizações, notificações, entre outras características, que estão comumente presentes em plataformas de participação social (Figura 2).

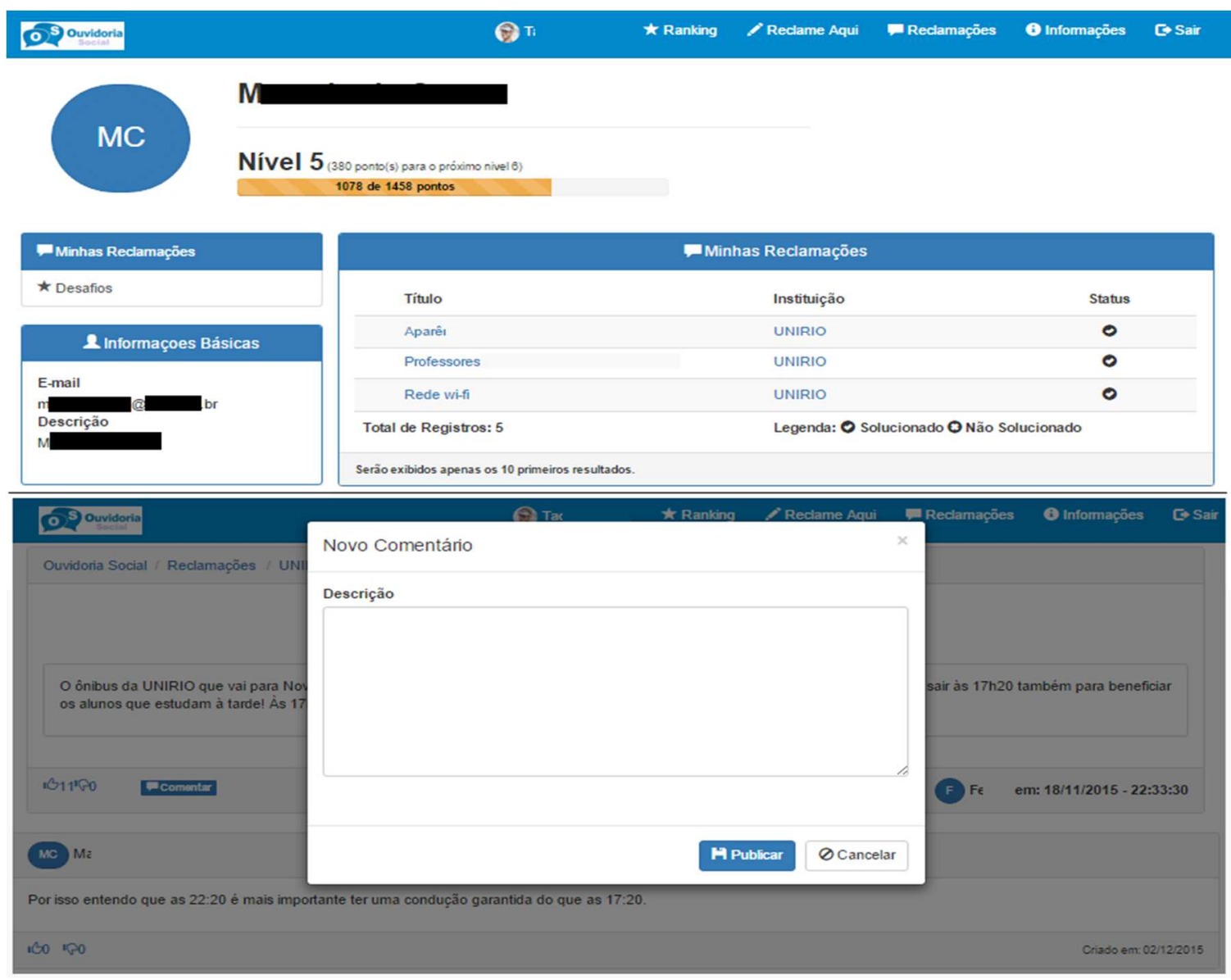

Figura 2. A) Perfil e informações do usuário. B) Reclamações, comentários, curtidas e descurtidas.

\footnotetext{
${ }^{6}$ Pacote de instalação da plataforma: https://sourceforge.net/projects/ouvidoria-social/files/v.1.0.0/

${ }^{7}$ Código fonte da plataforma (Git): https://sourceforge.net/p/ouvidoria-social/code/ci/master/tree/ 
Pensando nos níveis de participação eletrônica [Gomes 2004 apud Araujo et al., 2011], especificamente os níveis propostos no framework de Araujo e Taher (2014), o protótipo Ouvidoria Social pretende atuar no nível de prestação de serviço, onde seria possível exercitar a colaboração entre os usuários e memória por meio das mensagens, queixas, comentários e sugestões públicas.

Tratando-se de um ambiente gamificado, trabalhos como o de Bista e colaboradores (2012, 2014), Silva e Prado (2015) e Lounis e colaboradores (2014) serviram como fundamentos dos requisitos de design dos elementos de gamificação deste artefato; a escolha do mecanismo de gamificação influencia no comportamento dos usuários [Silva e Prado, 2015].

Os autores [Bista et al., 2012][Bista et al., 2014][Lounis et al., 2015][Horita et al, 2014][Moradian et al., 2014] destacam que os elementos de pontos, níveis, progresso, desafios, badges e ranking são considerados os mais comuns em processos de gamificação, por isso foram implementados no artefato como fonte de motivação intrínseca (Figura 3), pois tais mecanismos atuam no emocional dos usuários, sem oferecer um ganho real (lucro) para ele.

Outro elemento de gamificação incluído no experimento, foi o benefício de 0,5 pontos (recompensa) para os participantes da plataforma em uma disciplina do curso de Bacharelado em Sistemas de Informação (BSI) da UNIRIO, como fonte de motivação extrínseca, pois existe um benefício real, na tentativa de entender seus efeitos sobre a plataforma de participação.

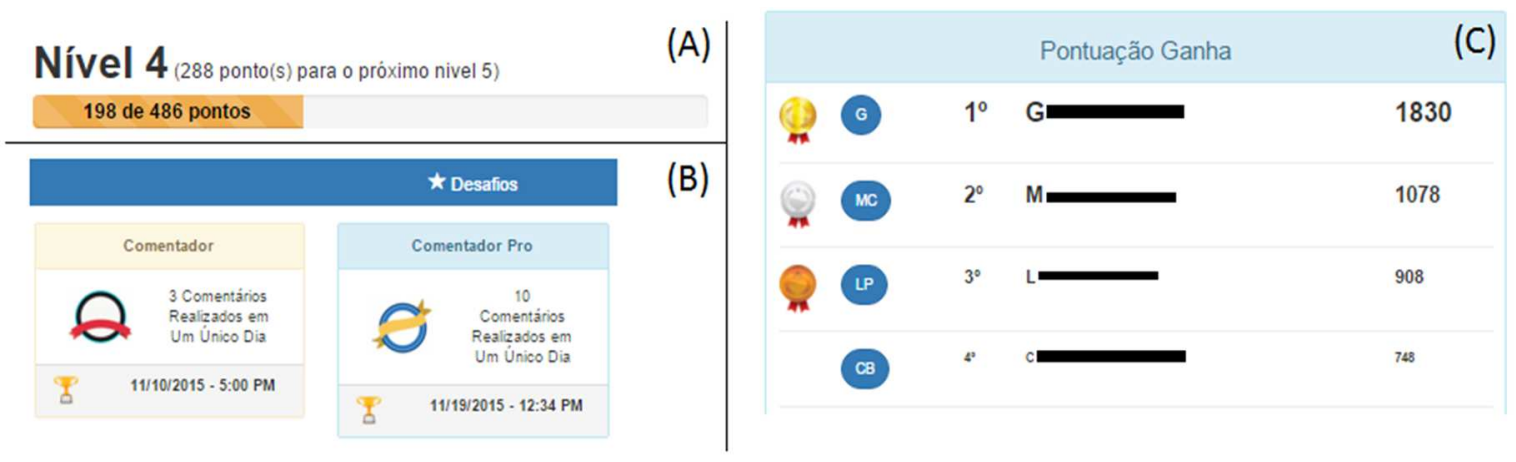

Figura 3. A) Pontos, Progresso e Níveis. B) Desafios e Badges. C) Ranking

O mecanismo de contagem de pontos na Plataforma consiste no somatório de todas as ações que podem ser executadas pelo usuário, podendo este contribuir para aumentar a pontuação de outros participantes ao curtir, comentar, ou acessar suas reclamações ou comentários; a Tabela 1 apresenta os critérios de pontuação.

Tabela 1 - Critérios de Pontuação na Plataforma de Participação Social Ouvidoria Social

\begin{tabular}{|c|c|c|c|}
\hline Critério & Pontuação & Critério & Pontuação \\
\hline Solucionar sua reclamação & 50 pontos & $\begin{array}{c}\text { Comentário marcado como } \\
\text { possível solução }\end{array}$ & 5 pontos \\
\hline Publicar reclamação & 10 pontos & Comentar uma reclamação & 3 pontos \\
\hline Cadastro de usuário & 5 pontos & Reclamação com mídia & 3 pontos \\
\hline Curtir reclamação & 2 pontos & Reclamação curtida & 2 pontos \\
\hline
\end{tabular}

CLASSE, T.; SILVA, J.; PIMENTEL, M.; ARAUJO, R.

Uma Experiência de uso da Gamificação em Plataformas de Participação Social

iSys - Revista Brasileira de Sistemas de Informação, Rio de Janeiro, vol. 9, No. 1, pp. 58-80, 2016 


\begin{tabular}{|c|c|c|c|}
\hline Acessar reclamação & 1 ponto & Descutir reclamação & 1 ponto \\
\hline Curtir comentário & 1 ponto & Comentário curtido & 1 ponto \\
\hline Descutir comentário & 1 ponto & Reclamação descurtida & -1 ponto \\
\hline Comentário descurtido & -1 ponto & $\begin{array}{c}\text { Comentário desmarcado como } \\
\text { possível solução }\end{array}$ & 5 pontos \\
\hline
\end{tabular}

\section{Avaliação}

Realizou-se, para a avaliação deste trabalho, um estudo experimental (método quantitativo) a fim de verificar se o uso de elementos de gamificação pode influenciar na participação dos usuários dentro da plataforma Ouvidoria Social. Após o experimento foi aplicado um questionário (método qualitativo) para avaliar o uso da Plataforma perante seus usuários e, também para verificar possíveis falhas e melhorias.

\subsection{Definição do Experimento}

O experimento tem como objetivo: analisar o uso de elementos de design de jogos em uma plataforma de participação social, com o objetivo de avaliação no que diz respeito ao aumento da participação dos usuários no ponto de vista do pesquisador no contexto dos alunos do curso de bacharelado em sistemas de informação da UNIRIO (Universidade Federal do Estado do Rio de Janeiro).

O estudo experimental visou avaliar a plataforma Ouvidoria Social em duas fases distintas (sem gamificação e usando gamificação) em um mesmo grupo (grupo pré e pós-teste). Essas fases buscaram avaliar o comportamento dos usuários perante o sistema, verificando as reclamações, curtidas, descurtidas, comentários e outras formas de interação.

No experimento foi considerado como variável independente de pesquisa a gamificação (uso de elementos de design de jogos). Sendo assim, foram considerados dois tratamentos a serem analisados: o uso da plataforma de participação social sem gamificação e; o uso da plataforma de participação social com gamificação. A variável dependente do experimento é a participação dos usuários, a qual foi calculada a partir de uma fórmula gerada com as funcionalidades (reclamações, comentários, curtidas, etc.) da plataforma de participação social (Figura 4). Com isso foi possível definir as hipóteses, comparando a plataforma usando gamificação com a plataforma sem uso da gamificação, como:

- H nula: O uso de gamificação NÃO AUMENTA a participação dos usuários em uma plataforma de participação social;

- H alternativa: O uso de gamificação AUMENTA a participação dos usuários em uma plataforma de participação social.

A Tabela 2 mostra como foi definido o processo de execução do experimento. Os participantes do experimento foram escolhidos baseados em conveniência, por exemplo, os participantes são alunos do curso de Bacharelado em Sistemas de Informação da UNIRIO da disciplina de Gerência de Projetos de Informática (18 alunos de graduação participantes) já que os mesmos são usuários de serviços de uma instituição pública. A primeira fase do experimento foi constituída do uso da Ouvidoria Social sem os mecanismos de gamificação pelo grupo de usuários. Em um primeiro

CLASSE, T.; SILVA, J.; PIMENTEL, M.; ARAUJO, R.

Uma Experiência de uso da Gamificação em Plataformas de Participação Social

iSys - Revista Brasileira de Sistemas de Informação, Rio de Janeiro, vol. 9, No. 1, pp. 58-80, 2016 
momento foi apresentada a plataforma através de um treinamento de 10 minutos, após isso o grupo a utilizaria por um período de 15 dias.

Tabela 2 - Planejamento do Experimento

\begin{tabular}{|c|c|c|}
\hline & Tópico & Tempo \\
\hline \multirow{3}{*}{ Fase 1 } & Treinamento & 10 minutos \\
\cline { 2 - 3 } & Experimento & 15 dias \\
\hline \multirow{3}{*}{ Fase 2 } & Treinamento & 10 minutos \\
\cline { 2 - 3 } & Experimento & 15 dias \\
\cline { 2 - 3 } & Questionário & 7 dias (dentro dos 15 dias) \\
\hline
\end{tabular}

Já na segunda fase, os usuários fariam o uso da plataforma Ouvidoria Social com gamificação utilizando mecanismos intrínsecos (como pontos, rankings, badges, desafios, etc.), da mesma maneira que na fase 1 do experimento, um treinamento de 10 minutos foi ministrado, exemplificando os mecanismos de gamificação disponíveis e como pontuar na plataforma. Após o treinamento, a Plataforma foi liberada para a participação durante um período de 15 dias.

Outro aspecto importante a ser considerado, é que em ambas as fases foi oferecida uma bonificação de 0,5 pontos (em cada uma das fases), para os alunos participantes do experimento, válidos para a disciplina de Gerência de Projetos de Informática. Como já mencionado anteriormente, para contabilizar o nível de participação de cada usuário do experimento uma medida matemática "P" (Figura 4) foi pensada, onde existem as variáveis que representam a quantidade de ações realizadas, com atribuição de pesos de acordo com a participação que representam (Tabela 3 ).

$$
P=(A \times 0,1)+(a \times 0,1)+(c \times 0,2)+(C \times 0,3)+(R \times 0,4)
$$

Figura 4 - Fórmula para cálculo de participação.

Tabela 3 - Peso de Participação

\begin{tabular}{|c|l|c|}
\hline Variável & \multicolumn{1}{|c|}{ Participação } & Peso \\
\hline A & Acesso à plataforma & 0,1 \\
\hline a & Acesso a reclamações & 0,1 \\
\hline c & Curtidas e Não Curtidas & 0,2 \\
\hline C & Comentário & 0,3 \\
\hline R & Reclamações & 0,4 \\
\hline
\end{tabular}

Após o término do experimento foi disponibilizado um questionário de avaliação para os participantes, a fim de verificar quais foram suas percepções sobre a plataforma, quais os mecanismos que mais e menos influenciaram em seu uso, quais motivos fizeram com que alguns não se sentissem motivados a utilizá-la, além de sugestões de melhorias a serem feitas. 


\subsection{Ameaças a Validade do Experimento}

A principal ameaça de conclusão deste experimento pode ser atribuída ao poder estatístico dos métodos de análise utilizados, devido a existência de vários métodos estatísticos e as diferentes formas como eles podem ser empregados. Visando diminuir tal ameaça foram utilizados métodos estatísticos mais adequados a cada situação e às escalas de variáveis utilizadas, verificando suas medidas intervalares e comportamento de normalidade, por exemplo.

Como ameaças internas são enumeradas:

1. Histórico de atividades dos usuários durante o uso da Plataforma na primeira fase de participação, fazendo com que eles já estejam acostumados às suas funcionalidades. Apesar de utilizar uma mesma ferramenta, a segunda fase propõe o uso da mesma de maneira diferente da primeira, com mecânica e funcionalidades diferentes.

2. Ameaça de desgaste devido ao tempo do estudo. Para minimizar isso, o tempo do estudo foi fixado em 30 dias, podendo os participantes executarem o experimento a qualquer momento dentro deste período.

3. Ameaça de construção, devido às expectativas do pesquisador. No intuito de minimizar tal efeito, o pesquisador não teria contato com o grupo, além do treinamento e notificações da plataforma (feedback de ranking, e informação de disponibilização do questionário).

4. Ameaça de moral, onde os estudantes podem reagir de forma positiva devido ao incentivo da primeira fase (0,5 pontos), a qual é uma estratégia de recompensa extrínseca. Para minimizar tal risco, foi fornecido o mesmo tipo de incentivo na segunda fase.

5. Ameaça de treinamento, onde os estudantes teriam um treinamento de 10 minutos sobre a utilização da Plataforma na primeira fase do experimento. Para minimizar este risco, na segunda fase também fora dado um treinamento de 10 para os estudantes mostrando as funcionalidades gamificadas da plataforma.

\subsection{Coleta e Análise dos Dados}

Os dados ${ }^{8}$ do estudo foram coletados durante e no final do experimento, compreendendo as medidas obtidas na primeira fase e na segunda fase. Além disso, durante o experimento (final da segunda fase), foram coletados os dados do questionário ${ }^{9}$ disponibilizado aos usuários.

Os resultados apresentados neste trabalho foram obtidos usando o $\mathrm{R}$ Statistical (3.2.2) com um nível de significância definido em 5\% (alpha $=0,05)$. A análise foi realizada comparando a primeira fase com a segunda fase a partir das medidas de participação calculada pela fórmula apresentada na Figura 4 e da quantidade de pontos dos usuários.

Em ambas as fases foram obtidas as estatísticas descritivas, no intuito de realizar a remoção dos outliers (valores extremos) das amostras (Tabela 4). A remoção consistiu na verificação da média e do desvio padrão na fase 1 (3,4 - desvio padrão - pontos

\footnotetext{
${ }^{8}$ Dados em: https://goo.g1/ky5YdX

${ }^{9}$ Questionário em: https://goo.gl/ky5YdX

ClASSE, T.; SILVA, J.; PIMENTEL, M.; ARAUJO, R.

Uma Experiência de uso da Gamificação em Plataformas de Participação Social

iSys - Revista Brasileira de Sistemas de Informação, Rio de Janeiro, vol. 9, No. 1, pp. 58-80, 2016
} 
acima ou abaixo da média) e na fase 2 (25,5 - desvio padrão - pontos acima ou abaixo da média).

Tabela 4 - Estatísticas Descritivas de Participação

\begin{tabular}{|c|c|c|c|c|c|}
\hline & Média & $\begin{array}{c}\text { Desvio } \\
\text { Padrão }\end{array}$ & Mín. & Mediana & Máx. \\
\hline Fase 1 & 2,5 & 3,4 & $\mathbf{0 , 9}$ & 1,4 & $\mathbf{1 0 , 9}$ \\
\hline Fase 2 & 15,4 & 25,5 & $\mathbf{0 , 4}$ & 3,6 & $\mathbf{1 0 3 , 4}$ \\
\hline
\end{tabular}

Para verificar a hipótese deste experimento com estes dados, foi examinado qual seria o teste estatístico mais apropriado a ser aplicado, para isso, o teste de Shapiro-Wilk [Shapiro e Wilk, 1965] foi usado para verificar se os dados seguem uma distribuição normal.

A primeira comparação executada, foi verificar se a medida de pontuação é correlacionada com o cálculo de participação dos usuários, sendo aplicados o teste de normalidade no cálculo de participação e na variável de pontos. Constatou-se que ambas as variáveis, participação (p-value $=4.729 \mathrm{e}-07<0,05)$ e pontos $(\mathrm{p}$-value $=1.868 \mathrm{e}-06<$ $0,05)$ não possuem comportamento de normalidade, portando o teste de correlação aplicado foi o teste de Correlação de Kendall [Kendall, 1946]. Após a aplicação do teste estatístico de correlação, observou-se que os dados são fortemente correlacionados e é possível rejeitar a hipótese de que não existam correlações entre participação e pontos (Kendall 0.6958 e p-value 2.116e-06 < 0,05) (observável pela comparação de participação e pontos das duas fases na Figura 5 e 6).

Sabendo que a medida de participação não segue o comportamento normal, a hipótese deste trabalho foi verificada através do teste de Wilcoxon [Narchar, 1998] (Tabela 4). Com este teste foi possível obter um valor menor que 0,05 (p-value 0.04892), sendo assim, através da aplicação do teste é possível afirmar com ao menos 95\% de certeza que o uso de gamificação aumentou a participação dos usuários na plataforma Ouvidoria Social. Por meio do teste de tamanho de efeito $\mathrm{A}_{12}$ [Vargha et al., 1996], foi possível também demonstrar que neste experimento a Plataforma com gamificação teve uma maior participação em aproximadamente $76 \%$ das vezes, ou seja, $76 \%$ dos usuários participantes utilizaram a plataforma mais na segunda fase do que na primeira.

Através da análise estatística do experimento foi possível evidenciar a hipótese deste trabalho mostrando que existem diferenças significativas entre a participação dos usuários na Plataforma sem e com gamificação. Analisando os gráficos da Figura 7 e Figura 8 é possível perceber que existem participantes que não participaram na primeira fase, mas participaram na segunda fase. Isso também se reflete na quantidade de acesso da Plataforma, que teve um aumento significativo em relação a alguns participantes.

CLASSE, T.; SILVA, J.; PIMENTEL, M.; ARAUJO, R.

Uma Experiência de uso da Gamificação em Plataformas de Participação Social

iSys - Revista Brasileira de Sistemas de Informação, Rio de Janeiro, vol. 9, No. 1, pp. 58-80, 2016 


\section{Participação}

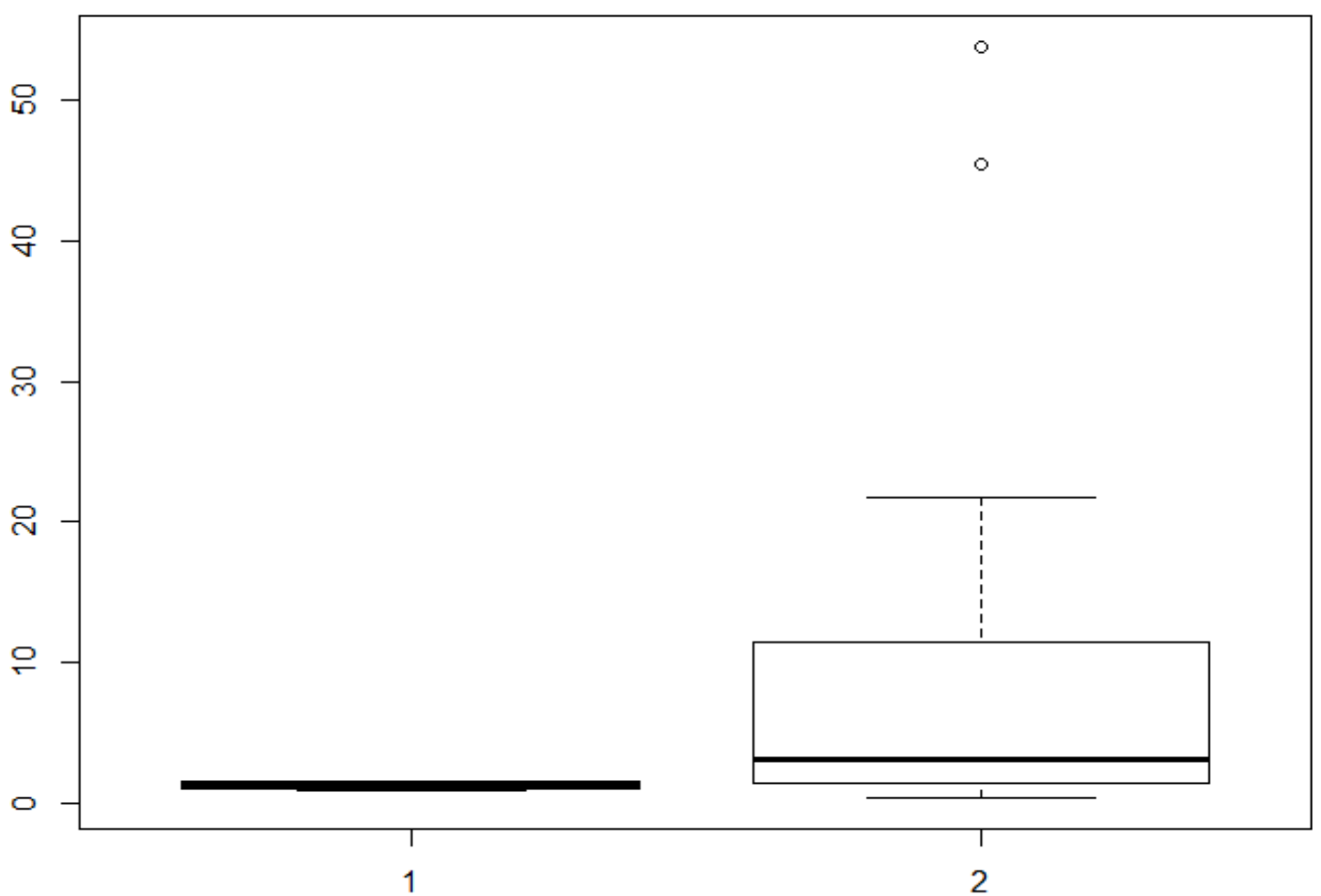

Figura 5 - Gráfico de participação da fase 1 e 2.

\section{Pontos}

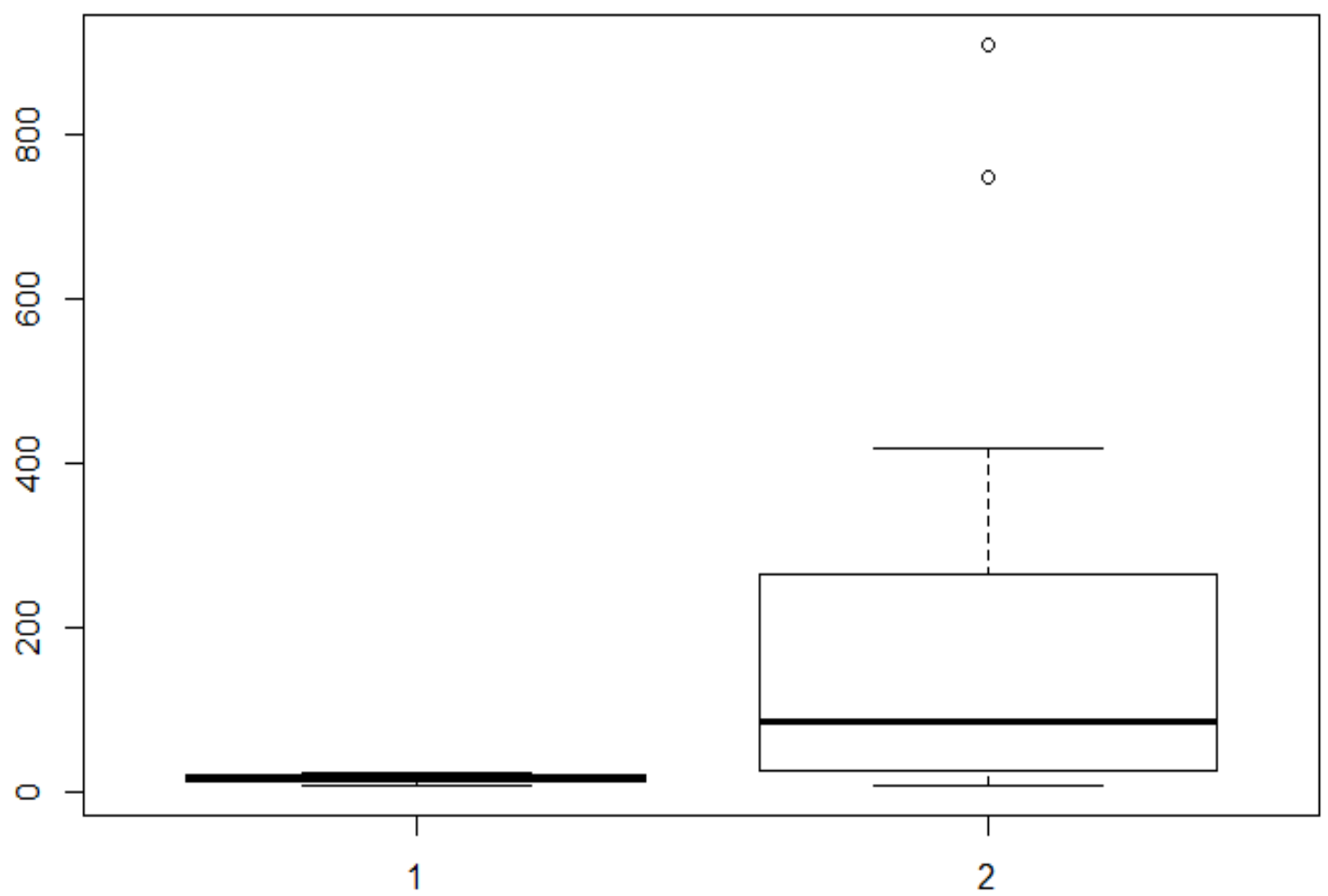

Figura 6 - Gráfico de pontos da fase 1 e 2.

CLASSE, T.; SILVA, J.; PIMENTEL, M.; ARAUJO, R.

Uma Experiência de uso da Gamificação em Plataformas de Participação Social

iSys - Revista Brasileira de Sistemas de Informação, Rio de Janeiro, vol. 9, No. 1, pp. 58-80, 2016 


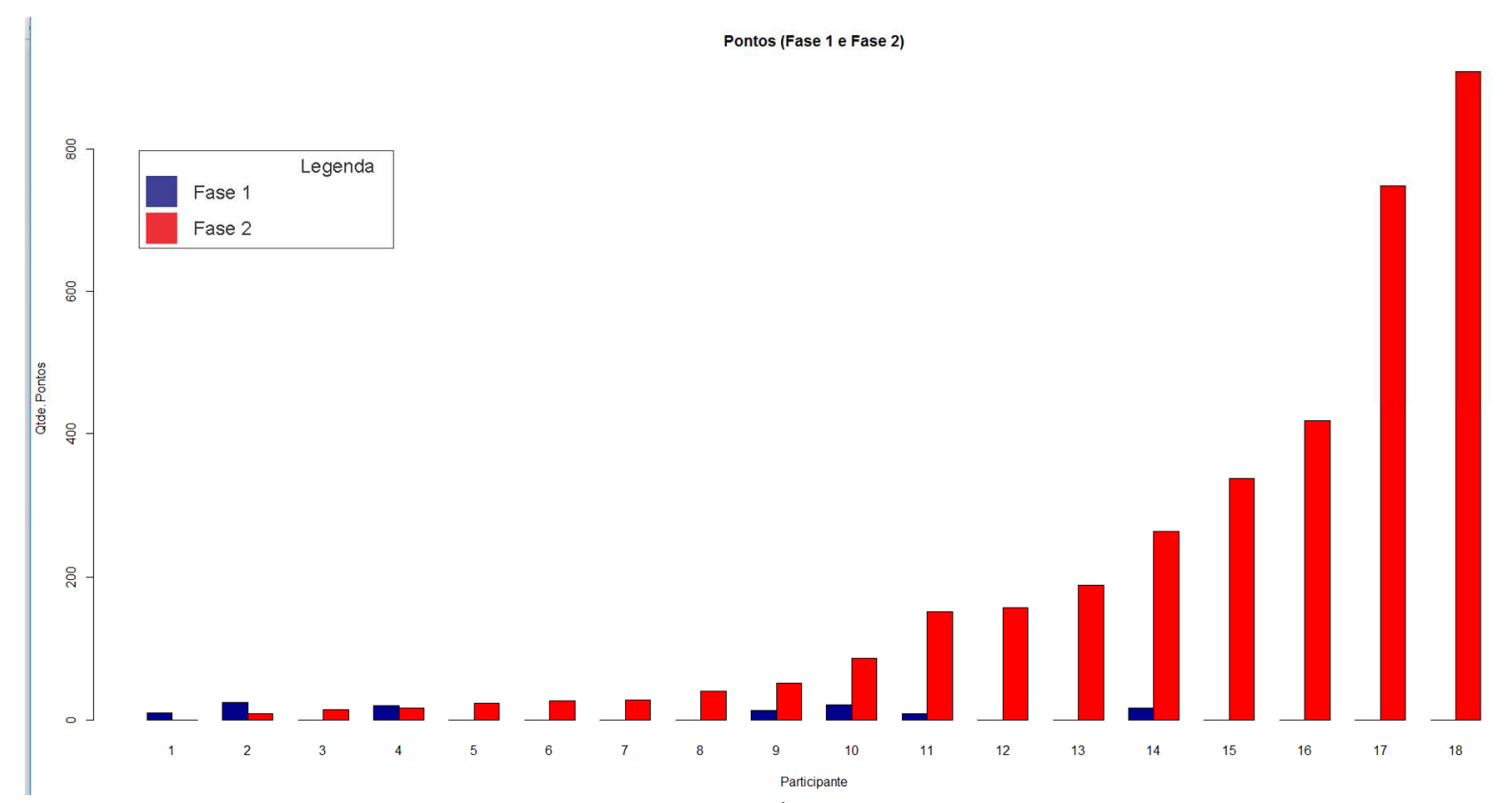

Figura 7 - Pontos dos usuários entre as fases 1 e 2.

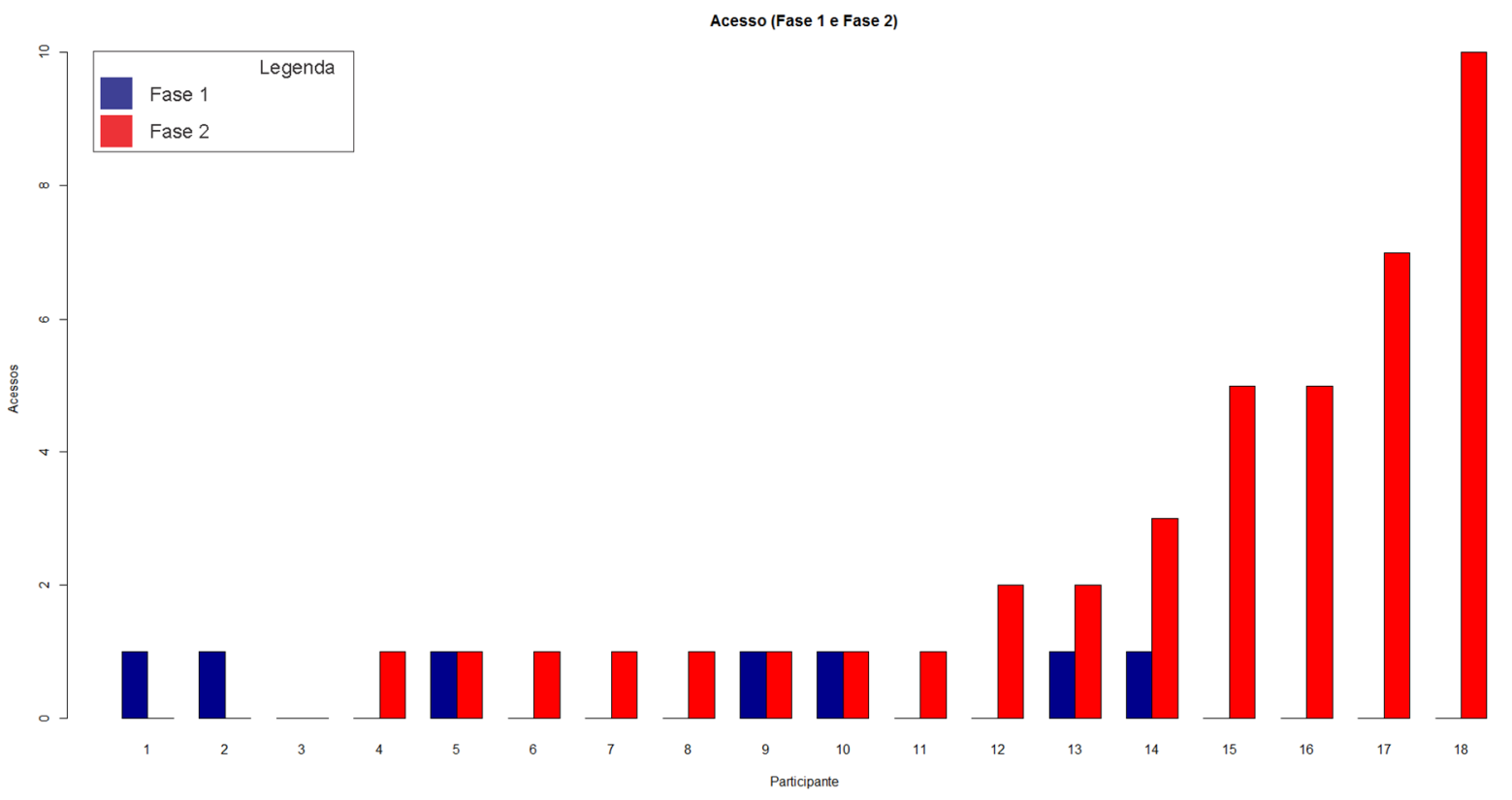

Figura 8 - Acessos dos usuários entre as fases 1 e 2.

\subsection{Análise das Respostas do Questionário de Pesquisa}

Conforme mencionado na subseção anterior, no final da segunda fase foi aplicado um questionário com o objetivo de avaliar questões relacionadas à motivação $\mathrm{e}$ desmotivação, mecanismos de gamificação e sugestões de melhorias na Plataforma. Neste sentido, um dos questionamentos foi "O que lhe motivou a utilizar a plataforma?", dentre os principais motivos destacados pelos alunos, o que mais motivou foi a possibilidade de contribuir com as melhorias da instituição $(81,8 \%)$, seguido da bonificação de pontos na disciplina de Gerência de Projetos de Informática $(72,7 \%)$, como pode ser visto na Figura 9. 


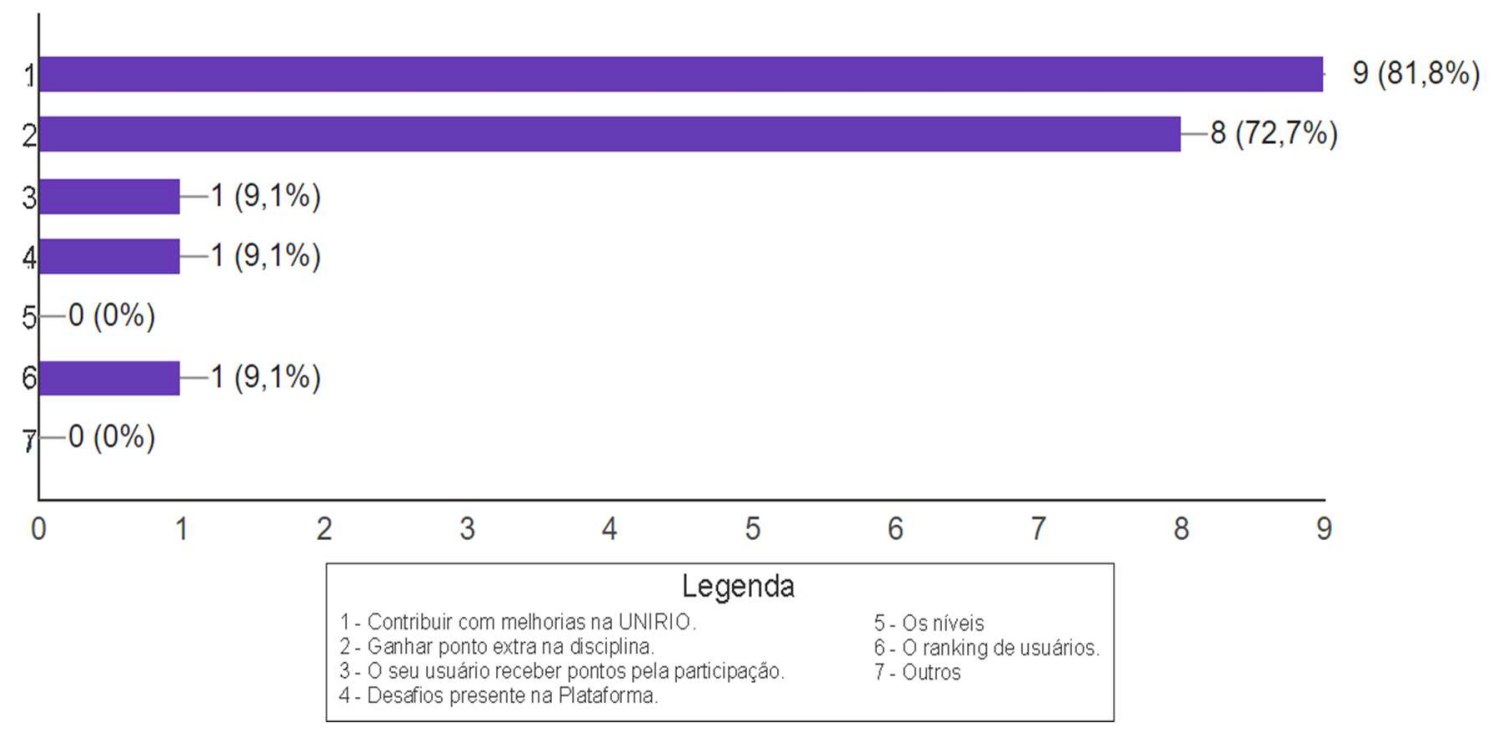

Figura 9 - Motivação de Uso da Plataforma.

Em relação à motivação, também foi formulada uma questão para tentar compreender quais mecanismos de gamificação mais influenciaram no comportamento dos usuários e conforme relato dos participantes, o mecanismo de gamificação que mais motivou a participação na Plataforma foi à bonificação de pontos na disciplina $(66,7 \%)$, seguido do mecanismo de desafio $(44,4 \%)$ (Figura 10). Conclui-se a partir destes dados, que a motivação extrínseca foi um forte atrativo (um gatilho) para a participação na Plataforma, entretanto, passados alguns dias, houve redução do nível de participação e interesse, acredita-se que os participantes que já haviam sido bonificados ficaram desestimulados a continuar interagindo.

Apesar de ser um gatilho, a motivação extrínseca pode promover a criação de conteúdos pouco relevantes [Ueyama et al., 2014], ou seja, uma pessoa extrinsecamente motivada é aquela que desempenha uma atividade ou tarefa interessado em recompensas externas [Leal et al., 2011], isso ficou claro no experimento, em que se percebeu que os participantes começaram a realizar postagens vazias, apenas para aumentar seus pontos no ranking e se mostrarem participativos no intuito de ganhar a bonificação de pontos da disciplina.

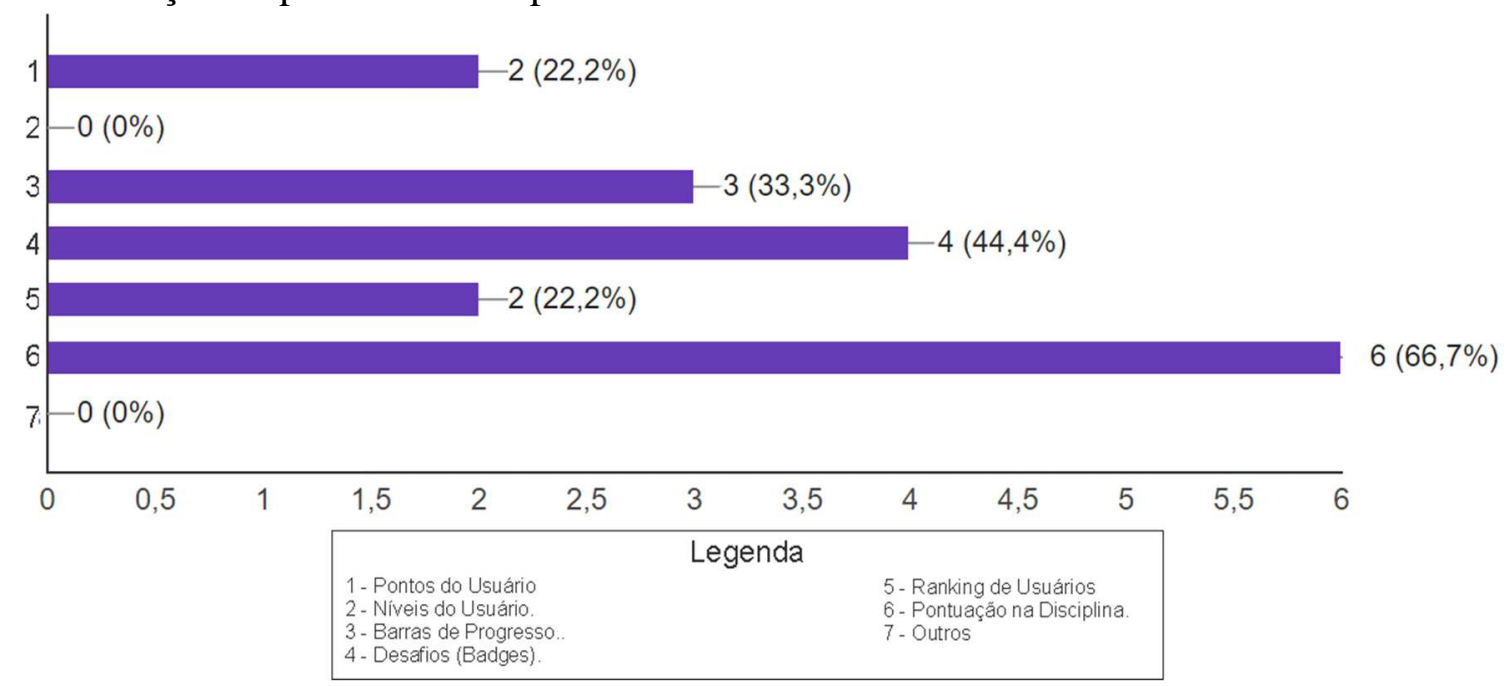

Figura 10 - Mecanismo de Gamificação.

ClASSE, T.; SILVA, J.; PIMENTEL, M.; ARAUJO, R.

Uma Experiência de uso da Gamificação em Plataformas de Participação Social

iSys - Revista Brasileira de Sistemas de Informação, Rio de Janeiro, vol. 9, No. 1, pp. 58-80, 2016 
Percebeu-se, mesmo com os mecanismos de gamificação empregados, que alguns alunos não realizaram nenhuma participação na Plataforma, para compreender os motivos da falta de interesse foi formulada a seguinte questão: "O que mais lhe desmotivou a utilizar a plataforma?" (Figura 11). Dentre os sintomas mais votados então a ausência da possibilidade de publicar e comentar de maneira anônima (50\%) e a plataforma não ser uma proposta dos gestores da UNIRIO (50\%), reduzindo a expectativa de resposta da instituições em relação as reclamações publicadas; alguns participantes reportaram que a institucionalização da Plataforma seria um fator de motivação.

O motivo relacionado a "Outros" $(33,3 \%)$ também merece atenção, pois aponta um mecanismo de gamificação como fator de desmotivação, relatando que o mecanismo de ranking estimula a competição entre os usuários ao invés de contribuir com a colaboração na resolução dos problemas. A interface também foi criticada pelos usuários, por, em muitos casos, não ser intuitiva.

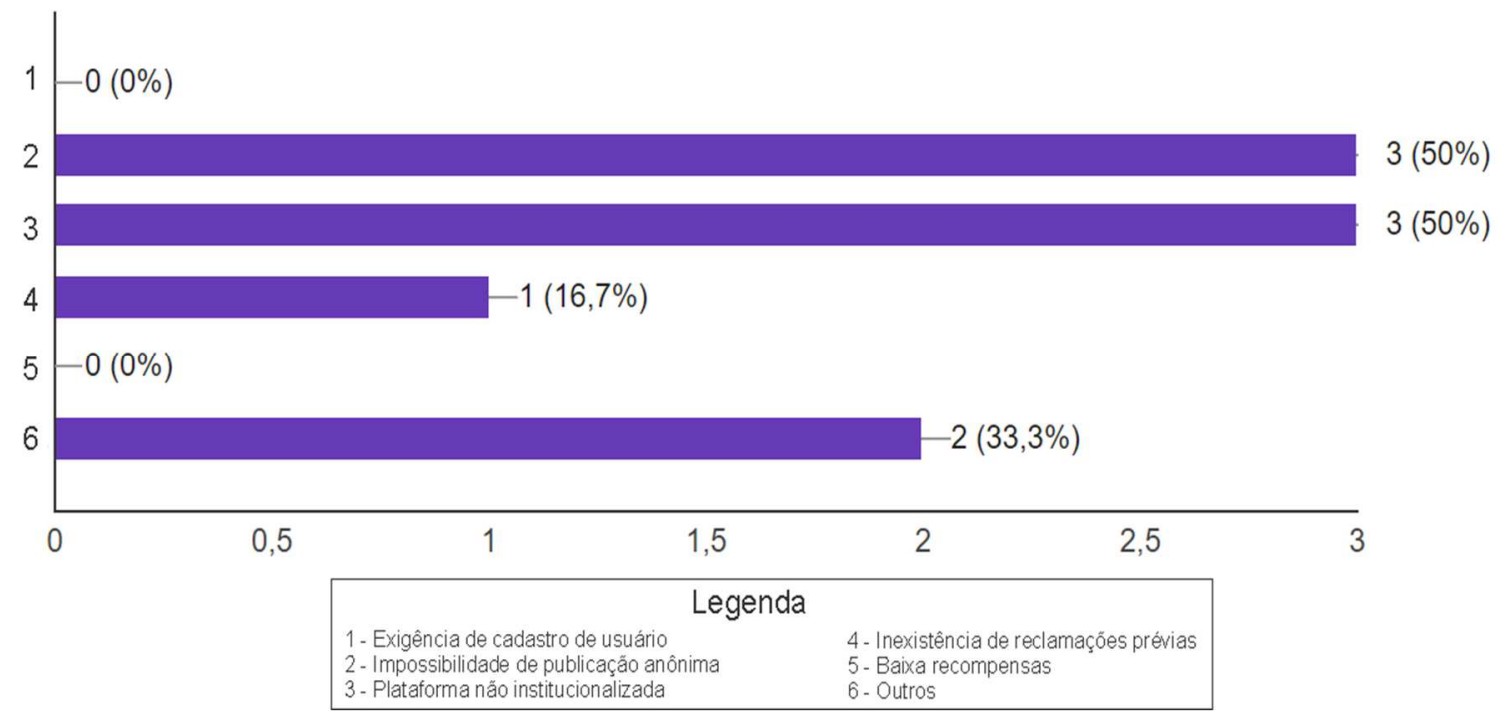

Figura 11 - Fatores que desmotivaram o uso da plataforma.

Perguntou-se, de maneira geral, para os participantes sobre a utilidade da Plataforma, como os mesmo a avaliariam, indo de completamente inútil para completamente útil. Nesta avaliação todos os participantes avaliaram a plataforma de útil a completamente útil (Figura 12).

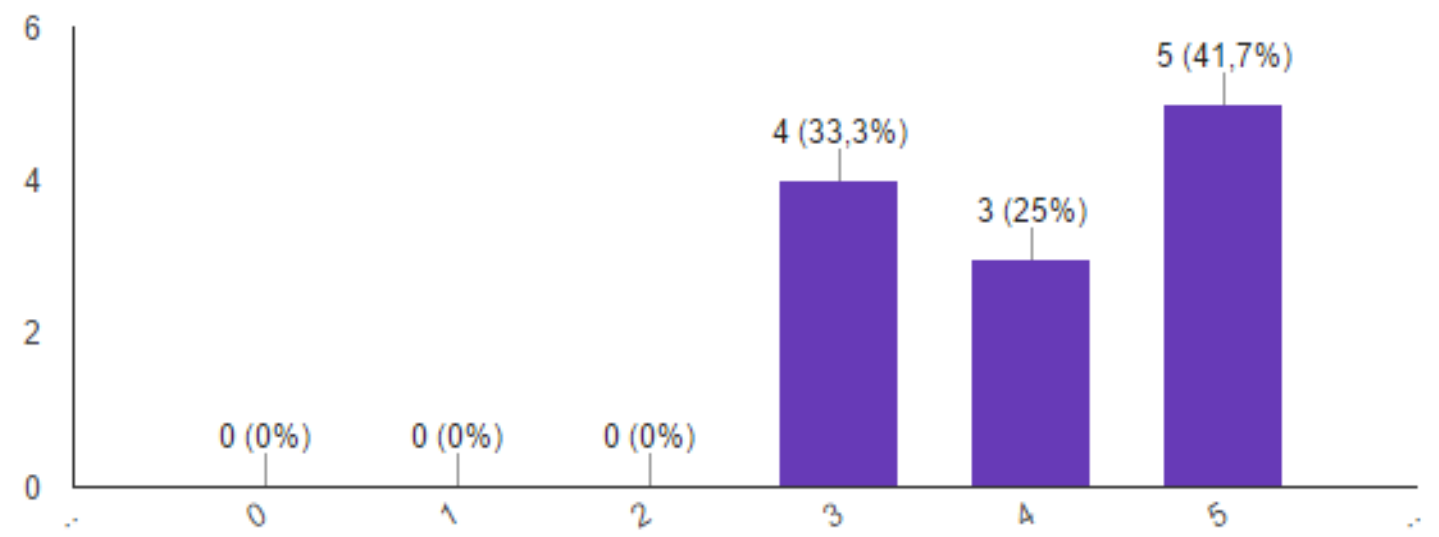

Figura 12 - Percepção de utilidade da plataforma. 
Além das questões supracitadas, sugestões de melhorias para incentivar a participação foram enviadas, tais como: institucionalização da Plataforma, deixando os alunos participarem do projeto; apresentar a plataforma e suas funcionalidades de forma gradativa para o usuário, com o objetivo de evitar que este tenha que aprender todas as funcionalidades ao mesmo tempo; apresentar o progresso das reclamações e enfatizar aquelas que foram solucionadas; melhorar os feedbacks da plataforma, permitindo que $o$ usuário mencionado em reclamações e comentários possam ser notificados; edição de reclamações e comentários.

No experimento, a motivação intrínseca foi utilizada no intuito de que todos os métodos empregados iriam motivar a participação e colaboração, porém um dos métodos mostrou o contrário, fazendo alguns usuários competirem e outros ficarem desmotivados. A motivação extrínseca também foi utilizada, mas ela mostrou que os participantes se entusiasmam a ganhar o benefício a qualquer custo, não importando se o conteúdo que estavam publicando era relevante ou não.

\section{Conclusão}

Existe uma grande oportunidade de pesquisa na investigação de mecanismos para motivar a interação do cidadão com o governo por meio do uso de tecnologias da informação e comunicação (TICs) para que estes participem, contribuam com o ciclo de políticas públicas, criação e melhoria de serviços ofertados pela administração pública e outros assuntos de interesse público. Esta pesquisa se concentrou na investigação do uso de elementos de gamificação para incentivar a participação cidadã por meio de plataformas de participação social.

Em relação a design science research (DSR), quanto a Ciência do Design, foi especificada e desenvolvida uma plataforma de participação social com elementos de gamificação, com o objetivo de resolver o problema da falta de motivação das pessoas para usar estes ambientes e exercitarem a participação cidadã. Após realizar uma pesquisa qualitativa quanto ao uso da plataforma, foram identificados quais elementos de gamificação tiveram maior influência sobre o comportamento das pessoas que usaram o ambiente, quais foram as dificuldades para usar estes e quais características os usuários consideram que devem estar presentes na plataforma, como publicações anônimas, curva de aprendizagem e disponibilização da plataforma Ouvidoria Social como uma proposta da instituição pública, possibilitando que esta responda as queixas.

Quanto a Ciência do Comportamento, esta pesquisa contribuiu para identificar como a implementação de elementos de gamificação em plataformas de participação social pode influenciar no comportamento dos indivíduos em relação ao uso destas plataformas e quais são as limitações destes mecanismos na motivação dos cidadãos. Concluiu-se que algumas formas de motivação intrínseca surtem efeitos desmotivadores neste contexto (como ranking gerando competições ao invés de colaboração), e outras surtem bons efeitos (como os desafios). Além disso, o mecanismo extrínseco empregado, contribuiu para aumentar a participação, entretanto, a qualidade das publicações foi comprometida.

O experimento mostrou que a gamificação exerceu influência sobre os cidadãos no contexto de participação eletrônica onde ela foi empregada, pois houve incremento da quantidade de publicações e acessos à Plataforma, entretanto, algumas técnicas de gamificação podem surtir efeitos desmotivadores e provocar a redução da qualidade das interações nas plataformas de participação social.

CLASSE, T.; SILVA, J.; PIMENTEL, M.; ARAUJO, R.

Uma Experiência de uso da Gamificação em Plataformas de Participação Social

isys - Revista Brasileira de Sistemas de Informação, Rio de Janeiro, vol. 9, No. 1, pp. 58-80, 2016 
Pretende-se, como trabalhos futuros, desenvolver um novo ciclo da DSR a partir da análise do experimento e dos dados coletados por meio da pesquisa qualitativa, e investigar quais atividades podem ser empregadas na engenharia de requisitos das plataformas de participação social para garantir uma participação continua (engajamento) e de qualidade dos cidadãos, reduzindo o distanciamento que ainda existe entre a sociedade civil e as instâncias governamentais, contribuindo para o fortalecimento da democracia participativa.

\section{Referências}

Araujo, R. M., Cappelli, C., Diirr, B., Engiel, P., Tavares, R. L. (2011) "Democracia Eletrônica". In: Pimentel, M., Fuks, H., Org. "Sistemas Colaborativos", 1ed, Rio De Janeiro: Campus/Sbc, p. 110-121.

Araujo, R., Taher, Y. (2014) "Refining IT Requirements for Government-Citizen Coparticipation Support in Public Service Design and Delivery", Conference for EDemocracy and Open Governemen, v.61.

Baykurt, B. (2012) "Redefining Citizenship and Civic Engagement: political values embodied in FixMyStreet.com", Selected Papers of Internet Research, v1.

Bista, S. S. K., Nepal, S., Colineau, N., Paris, C. (2012) "Using Gamification in an Online Community", Proceedings of the 8th IEEE International Conference on Collaborative Computing: Networking, Applications and Worksharing, p. 611-618.

Bista, S. S. K., Nepal, S., Colineau, N. (2014) "Gamification for Online Communities: A Case Study for Delivering Government Services", International Journal of Cooperative Information Systems, v. 23(02), p. 1441002.

Blohm, I., Leimeister, J. M. (2013) "Gamification: Design of IT-based enhancing services for motivational support and behavioral change", Business and Information Systems Engineering v. 5(4), p. 275-278.

Classe, T., Araujo, R. (2015), "Gamificação Para Participação Social Em Processos Públicos: Mapeamento Sistemático", Simpósio Brasileiro de Sistemas Colaborativos (SBSC), p. 130-137.

Connolly, T.M., Boyle, E.A., Macarthur, E., Hainey, T., Boyle, J.M. (2012) “A Systematic Literature Review of Empirical Evidence on Computer Games and Serious Games", Computers \& Education, Elsevier Ltd, v. 59(2), p. 661-686.

Deterding, S., Dixon, D., Khaled, R., Nacke, L. (2011) "From game design elements to gamefulness", Proceedings of the 15th International Academic MindTrek Conference on Envisioning Future Media Environments - MindTrek '11, p. 9-11.

Dialogra Brasil. (2015), "Quantitativo de Usuários". Disponível em: <http://dialoga.gov.br/>. Acesso em 20 de dezembro de 2015.

Dresch, A., Lacreada, D. P., Atunes Júnior, J. A. (2015) "Design Science research: método de pesquisa para avanço da ciência e tecnologia", Porto Alegre: Bookman.

Effing, R., Hillegersberg, J. V., Huibers, T. (2011) "Social Media and Political Participation: Are Facebook, Twitter and YouTube Democratizing Our Political Systems?", ePart 2011. p. 25-35.

CLASSE, T.; SILVA, J.; PIMENTEL, M.; ARAUJO, R.

Uma Experiência de uso da Gamificação em Plataformas de Participação Social

iSys - Revista Brasileira de Sistemas de Informação, Rio de Janeiro, vol. 9, No. 1, pp. 58-80, 2016 
Freire, F. R., Stabile, M. (2013) "As novas Tecnologias e a Participação Eletrônica: entre Promessas e Desafios", Pesquisa sobre o uso das tecnologias da informação e comunicação no setor público: TIC Governo Eletrônico. Comitê Gestor da Internet no Brasil, p. 47-56. Disponível em: 〈http://www.cgi.br〉. Acesso em: $01 \mathrm{de}$ dez. 2015 .

Gartner, (2015) Gartner Says By 2015, More Than 50 Percent of Organizations That Manage Innovation Processes Will Gamify Those Processes: 2011. http://www.gartner.com/newsroom/id/1629214. Accessed: 2015-05-25.

Gee, J.P. (2007) "What Video Games have to Teach us About Learning and Literacy", Palgrave Macmillan Ltd., New York, NY, 1st ed.

Gomes, W. (2004) "Transformações da política na era da comunicação de massa”, São Paulo: Paulus.

Hamari, J., Koivisto, J., Sarsa, H. (2014) "Does gamification work? - A literature review of empirical studies on gamification", Proceedings of the Annual Hawaii International Conference on System Sciences, p. 3025-3034.

Hevner, A., March, S., Park, J., Ram, S. (2004) "Design Science in Information Systems Research", MIS Quarterl, v. 28(1), p. 75-105.

Horita, F.E.A., Assis, L.F.F.G., Castanhari, R.E.S., Isotani, S., Cruz, W.M., Albuquerque, J.P. (2014) "A Gamification-based Social Collaborative Architecture to Increase Resilience Against Natural Disasters", Simpósio Brasileiro de Sistemas de Informação (SBSI), Londrina, Brazil.

Kendall, M. G. (1946) "The advanced theory of statistics", The advanced theory of statistics, 2ed.

Kleinman, D., Delborne, J. A., Anderson, A. A. (2009) "Engaging citizens: The high cost of citizen participation in high technology", Public Understanding of Science.

Leal, E.A., Miranda, G. J., Carmo, C. T. S. (2011) "Self-Determination Theory: An Analysis of Student Motivation in an Accounting Degree Program", III Encontro de Ensino e Pesquisa em Administração e Contabilidade/EnEPQ, v.24(62). p. 162-173.

Lounis, S., Pramatari, K., Theotokis, A. (2014) "Gamification Is All About Fun: the Role of Incentive Type and Community Collaboration", ECIS 2014 Proceedings, p. $1-14$.

Macintosh, A. (2004) "Characterizing e-participation in policy-making. In System Sciences, 2004", Proceedings of the 37th Annual Hawaii International Conference on IEEE, p. 10.

Magdaleno, A. M., Araujo, R. M. (2015) "Ecossistemas Digitais para o Apoio a Sistemas de Governo Abertos e Colaborativos", Simpósio Brasileiro de Sistemas de Informação (SBSI).

Menezes, G. S., Tarachucky, L., Pellizzoni, R. C., Perassi, R., Gonçalves, M. M., Gomez, L. S. R., Fialho, F. A. P. (2014) "Reforço e recompensa: a Gamificação tratada sob uma abordagem behaviorista", Projetica, v. 5(2), p. 9-18.

Moradian, A., Nasir, M., Lyons, K., Leung, R., Sim, S. E. (2014) "Gamification of collaborative idea generation and convergence", Proceedings of the extended

ClASSE, T.; SILVA, J.; PIMENTEL, M.; ARAUJO, R.

Uma Experiência de uso da Gamificação em Plataformas de Participação Social

iSys - Revista Brasileira de Sistemas de Informação, Rio de Janeiro, vol. 9, No. 1, pp. 58-80, 2016 
abstracts of the 32nd annual ACM conference on Human factors in computing systems - CHI EA '14, p. 1459-1464.

Narchar, N. (2008) "The Mann-Whitney U: a test for assessing whether two independent samples come from the same distribution", Tutorials in Quantitative Methods for Psychology, v. 4(1), p. 13-20.

Nielsen, J. (2006) "Participation inequality: Encouraging more users to contribute", Jakob Nielsen's alertbox. Disponível em: $<$ http://www.useit.com/alertbox/participation_inequality.html $>$. Acesso em: $20 \mathrm{de}$ dezembro de 2015.

Participa.BR (2015) "Quantitativo de Usuários", Disponível em: <http://www.participa.br/>. Acesso em 20 de dezembro de 2015.

Recker, J. (2012) "Scientific research in information systems: a beginner's guide", Springer Science \& Business Media.

Richard M. R., Edward L. D. (2000). "Intrinsic and Extrinsic Motivations: Classic Definitions and New Directions", Contemporary Educational Psychology, v.25(1), p. 54-67.

Rocha, E. B., Pimentel, M., Diniz, M. C., Santoro, F. M. (2015) "Design Science Research para o Desenvolvimento de um Modelo da Participação em Bate-papo", iSys-Revista Brasileira de Sistemas de Informação, v. 8(1), p. 18-41.

Sæbø, Ø., Rose, J., Flak, L. S. (2008) "The shape of eParticipation: Characterizing an emerging research area", Government information quarterly, v. 25(3), p. 400-428.

Santos, J. U. D. L., Corso, K. B., Behr, A., Farias, E. S. (2015a) "CIDADÃOS EM REDE: o gabinete digital do Estado do Rio Grande do Sul como instrumento de democracia digital", Revista Democracia Digital e Governo Eletrônico, v. 1(12), p. 150-182.

Santos, A.C.; Zambalde, A.L.; Veronese, R.B.; Botelho, G.A.; Souza Bermejo, P.H. (2015b) "Open Innovation and Social Participation: A Case Study in Public Security in Brazil", Electronic Government and the Information Systems Perspective, p. 163173.

Shapiro, S.S., Wilk, M. B. (1965) "An analysis of variance test for normality (complete samples)”, Biometrika, p. 591-611.

Silva, C. M. C., Prado, P. V. P. (2015) "Estudo sobre o engajamento de usuários de uma mídia social disponibilizada pelo governo", XI Simposio Brasileiro de Sistemas de Informação.

Silva, J., Araujo, R. (2015) "Metodologias para o Desenvolvimento de Sistemas para Participação Eletrônica: Mapeamento Sistemático", Relatórios Técnicos do Departamento de Informática Aplicada da UNIRIO, v. 8(1), Rio de Janeiro.

Simões, J., Redondo, R.D., Vilas, A. F. (2013) “A social gamification framework for a K-6 learning platform”, Computers in Human Behavior, v. 29(2), p. 345-353.

Tambouris, E., Liotas, N., Tarabanis, K. (2007) "A framework for assessing eParticipation projects and tools", System Sciences, 2007. HICSS 2007. 40th Annual Hawaii International Conference on. IEEE, p. 90-90.

CLASSE, T.; SILVA, J.; PIMENTEL, M.; ARAUJO, R.

Uma Experiência de uso da Gamificação em Plataformas de Participação Social

iSys - Revista Brasileira de Sistemas de Informação, Rio de Janeiro, vol. 9, No. 1, pp. 58-80, 2016 
Thiel, S. (2015) "Gamified participation: investigating the influence of game elements in civic engagement tools", Proceedings of the 2015 ACM International Joint Conference on Pervasive and Ubiquitous Computing and Proceedings of the 2015 ACM International Symposium on Wearable Computers, p. 527-532.

Ueyama, Y., Tamai, M., Arakawa, Y., Yasumoto, K. (2014) "Gamification-based incentive mechanism for participatory sensing" 2014 IEEE International Conference on Pervasive Computing and Communication Workshops, PERCOM WORKSHOPS, p. 98-103.

Vargha, A., Delaney, H. D., Rudas, T., Maxwell, S. E. (1996) "Dichotomization, partial correlation, and conditional independence", Journal of Educational and Behavioral statistics, v. 21(3), p. 264-282. 